\title{
Investigating effect of Helicobacter pylori treatment on improvement of non- alcoholic fatty liver parameters: a randomized trial
}

Amir Mohammad Kazemifar', Ali Akbar Shafikhani², Elaheh HajiNoormohammadi ${ }^{3}$,Zahra Azarion ${ }^{3}$ and Aliakbar Hajiaghamohammadi ${ }^{4^{*}}$

\begin{abstract}
Background and objective: The correlation between the eradication of Helicobacter pylori (HP) and non-alcoholic fatty liver disease (NAFLD) is a controversial one. The aim of this study is to investigate the effect of Helicobacter pylori treatment on liver function tests and lipid profiles and to compare its effects with exercise therapy and diet alone.

Method: This was a double-blind randomized clinical trial conducted at Qazvin University of Medical Sciences. One hundred patients with NAFLD having a positive test for urea breath testing were randomly assigned into one of the intervention and comparison groups. The diet and physical activity program were given to two groups of patients for 8 weeks, three sessions per week. In addition to the above therapy, the patients in the intervention group also received HP treatment for 2 weeks. The data corresponding to anthropometric and clinical features before and after the intervention were collected in both groups and compared using appropriate statistical methods.

Results: After the treatment interventions, the variables of weight, BMI, blood glucose, triglyceride, AST, ALT, total cholesterol, and LDL-C were significantly decreased in both groups $(p<.05)$. In the between-group comparisons, only ALT was significantly lower in the intervention group (HP) $(p<.05)$.

Conclusion: Findings of this study showed that the eradication of Helicobacter pylori could significantly improve the ALT index, but it had no additional effect on changes in metabolic indicators.

Trial registration: Registration number: IRCT2015042020951N2

Name of trial registry: The study of treatment of Helicobacter pylori in improvement of non-alcoholic fatty liver disease The date of registration: 2015-05-12

Where the full trial protocol can be accessed: https://fa.irct.ir/trial/18489
\end{abstract}

Keywords: Non-alcoholic fatty liver disease, Helicobacter pylori, Alanine transaminase, Aspartate aminotransferases

\section{Background}

Non-alcoholic fatty liver disease (NAFLD) is a type of liver injury caused by metabolic stress and hereditary sensitivity. Generally, this disease is considered to be the liver manifestation of the metabolic syndrome [1, 2]. NAFLD includes non-alcoholic fatty liver (NAFL), non-alcoholic steatohepatitis (NASH), and non-alcoholic steatohepatitis associated

\footnotetext{
*Correspondence: ahmohammadi@qums.ac.ir

${ }^{4}$ Gastroenterologist Metabolic Diseases Research Center, Qazvin University of Medical Sciences, Qazvin, Iran

Full list of author information is available at the end of the article
}

with hepatic cirrhosis and hepatocellular carcinoma. The incidence of NAFLD complications is rapidly increasing in the world [2, 3]; therefore, the economic and clinical burden of this disease is significant. Recently, except for the known risk factors such as obesity, type 2 diabetes, hypertension, and dyslipidemia, the role of the pathogenesis of Helicobacter pylori (HP) is also discussed in the disease and may be associated with NAFLD $[4,5]$.

HP is a Gram-negative bacterium that is selectively placed in the gastric mucosa. This bacterium is the cause of most cases of gastric ulcers and leads to development of some 
gastro-intestinal cancers. However, this microbe does not cause cancer in all people [6,7]; nearly $15 \%$ of patients with long-term infections might have one or more complications. According to estimates, about $25-50 \%$ of people in the developed countries and $70-90 \%$ of people in the developing countries are infected with this bacterium. The higher the age, the greater the chance of infection would be [7-9].

Recently, the HP infection has been implicated in nondigestive diseases, cardiovascular diseases, type 2 diabetes, and iron deficiency anemia $[6,10,11]$. In previous theories, Taylor et al. pointed out these cases and said that the HP species can cause damage to liver cells with the production of liver toxins [12]. Recently, HP infection has been reported as one of the risk factors for the development of non-alcoholic fatty liver disease [13]. However, recent findings have been focused on the correlation between HP infection and NAFLD, and their results are contradictory. On the one hand, Polyzos et al. showed that the eradication of $\mathrm{HP}$ infection might provide specific therapeutic approaches to NAFLD treatment. On the other hand, Jamali et al. presented contradictory results [14].

This study aimed to evaluate the effect of HP eradication on the liver function tests and lipid profiles and to compare its effects with diet and exercise therapy. Given the relatively high prevalence of HP infection in Iranian patients [15] and high prevalence of fatty liver [16], it could be significantly important to establish a correlation between the two abovementioned factors and eradicate it in the fatty liver treatment in Iran.

\section{Method}

The present research was a clinical trial with the preand post-test design, which was carried out at Velayat Hospital, Qazvin University of Medical Sciences. The statistical population of this research was the patients who were investigated for evaluating high levels of aspartate aminotransferase (AST) and alanine aminotransferase (ALT) (above 40 units per liter). From among the patients visiting Velayat Hospital, Qazvin Province, 105 NAFLD patients who had a positive urea breath test were selected randomly. Then, the participants were divided into two groups of intervention and comparison with a one-to-one ratio using a computer block method. This study was approved by the Ethics Committee of Qazvin University of Medical Sciences, and the participation of individuals was subject to a written consent.

The inclusion criteria were the age of above 12 years old, positive results for HP antibodies (in serological tests), and evidence of fatty liver in ultrasonography. It should be noted that the use of any therapeutic strategy for HP and any factors affecting aminotransferase were classified as the exclusion criteria.

The patients in both groups received lifestyle changes as the standard treatment. The lifestyle changes in both groups included moderate to intense exercises such as walking, running, swimming, and cycling for 45-60 min at least 3 days per week in all the patients for 8 weeks. Furthermore, the participants were asked to follow a certain diet. The diet included the reduced starchy, glucose, and oil. A nutritionist who was unaware of the study protocol implemented the treatment and examined the daily calorie intake of people during the study period. In addition to the above treatment, the intervention group underwent a standard treatment of clarithromycin, amoxicillin, and omeprazole for 2 weeks in order to eradicate the HP infection.

All the patients underwent anthropometric tests including height, weight, and body mass index (weight per $\mathrm{kg}$ divided by height per $\mathrm{m}^{2}$ ). Weight and height were measured in straight and upright postures while wearing light underwear and no shoes. The waist circumference of the participants was measured in $\mathrm{cm}$ in the intermediate region of the lower margin of the ribs and anterior superior iliac crest. A radiologist who was unaware of the clinical data of the patients and data allocation performed the liver ultrasound. The fatty liver was diagnosed by echo with a $3.5-\mathrm{MHz}$ probe. All the patients were examined by the physician, and the necessary tests (routine fasting blood biochemistry) such as fasting blood glucose, high-density lipoprotein (HDL) cholesterol, and lowdensity lipoprotein (LDL) cholesterol were carried out. The blood pressure was measured periodically using a 2$\mathrm{mmHg}$ graded sphygmomanometer after $5 \mathrm{~min}$ of resting. The blood samples were taken after $12 \mathrm{~h}$ of fasting, and then, the blood tests were run. Fasting blood glucose was measured by glucose oxidase method [17, 18], lipid profiles (total triglyceride and cholesterol), and HDL using immunocolorimetric assay and LDL by Friedewald formula [19]. In order to measure ALT and AST, the enzymatic methods were used [20]. The laboratory researchers were unaware of the intervention or allocation of the comparison group. All of the indicators were compared in the base and post-intervention modes (1 month later).

\section{Statistical analysis}

In this research, the descriptive statistics was used to show the central and dispersion indicators, and Kolmogorov-Smirnov test was employed for evaluating the normality of the data distribution. A paired $t$-test was used to assess the within-group difference in the anthropometric and biochemical variables. Additionally, to investigate the effect of the intervention on biochemical and demographic variables, the independent $t$-test was used for difference in the scores. All the statistical analyses were performed using SPSS V.23, and a $p$ value of $<0.05$ was considered significant. 


\section{Results}

From 105 patients, 100 patients with the mean age of $37.63 \pm 10.33$ years old were included. Five patients were excluded due to unwillingness to continue the study. Table 1 shows the baseline characteristics of the participants in both groups. There was no significant difference between the two groups in terms of age, sex, and fatty liver level.

Table 2 shows anthropometric measurements between the treatment groups. Regarding the within-group analysis, both treatment groups were significantly improved in terms of variables such as weight, BMI, and waist circumference $(p<.05)$. Between-group analysis regarding the variables of weight, BMI, and waist circumference showed no significant difference between the two groups $(p>.05)$.

Table 3 shows the comparison of laboratory parameters between the treatment groups. The within-group analysis showed a significant reduction in the intervention and comparison groups regarding the variables of blood glucose, total cholesterol, triglyceride, HDL, LDL, AST, and ALT $(p<0.05)$. In the intervention group, the between-group statistical analysis on the ALT variable showed a significant reduction $(p<.05)$. No significant relationship was observed between the two groups in terms of other variables. In this study, no adverse side-effects occurred following the HP treatment. Moreover, there was no need to reduce or stop the treatment dose.

\section{Discussion}

This study was designed to answer the uncertainties regarding the effectiveness of HP treatment in nonalcoholic fatty liver patients. The results showed that the ALT indicator was reduced more in the intervention group (HP treatment) than the comparison group. This indicator is highly important in the liver injury, so it can be argued that the eradication of HP has a significant effect on the improvement of patient's fatty liver. These results were consistent with Polyzos et al.'s findings. In a research, they

Table 1 Baseline characteristics of participants in two treatment groups

\begin{tabular}{lllr}
\hline Variable & Intervention group & Comparison group & $p$ value \\
\hline Age (year) & $36.88 \pm 11.50$ & $38.38 \pm 9.06$ & 0.47 \\
Sex & & & \\
$\quad$ Male & $23(46 \%)$ & $21(42 \%)$ & 0.68 \\
$\quad$ Female & $27(54 \%)$ & $29(58 \%)$ & \\
Fatty liver level & & 0.72 \\
Grade 1 & $25(50 \%)$ & $29(58 \%)$ & \\
Grade 2 & $20(40 \%)$ & $17(34 \%)$ & \\
Grade 3 & $4(8 \%)$ & $5(10 \%)$ & \\
\hline
\end{tabular}

showed that treatment of HP infection was effective in the improvement of fatty liver [21]. In contrast to the present study, Jamali et al. in Tehran [14] and Okushin et al. in Japan showed that the eradication of HP had no positive effect on the fatty liver of the patients [22]. Probably, one of the most important factors involved in different results is the eradication method of HP, duration of dietary intervention, nature of exercise, intensity and volume of aerobic exercise, and individual differences. In the present study, contrary to Jamali et al. [14], the diet therapy was considered for 8 weeks. Afterwards, in the intervention group, the eradication of HP was performed for 2 weeks. This strategy could have led to different results. Studies on this topic have shown that significant changes in serum aminotransferase level of the patients with NASH followed by diet therapy require interventions for more than 8 weeks [23]; this could be a reasonable justification for differences between studies.

Results of the present study demonstrated a significant decrease in body weight index, waist circumference, and BMI in two groups, while no significant difference was found between two groups of intervention and comparison with regard to these indicators. One of the reasons for the improvement of these indicators in both groups could be the calorie intake restriction or aerobic exercises. Studies on this field have shown that the most prevalent treatment for obesity and fatty liver is daily calorie restriction. Since weight loss through daily calorie restriction is often limited and reversible, in addition to calorie intervention, exercise was also given to two therapy groups. Slancy et al. said that aerobic exercises can lead to reduced abdominal and visceral fat [24], so it is thought that simultaneous exercise and diet can be effective in weight loss in both groups.

In the present study, a significant decrease was seen in the variables of triglyceride, total cholesterol, LDL, and HDL in both groups, while no significant difference was observed between the two groups. These findings were consistent with the study by Park et al., who showed exercise could lead to a significant change in all lipid indicators [25].

Since no significant difference was seen between the intervention and comparison groups, it can be argued that exercise leads to significant changes in lipid indicators in both groups.

A significant improvement was found in the blood glucose index in both groups, whereas the difference between the two groups was not considerable. Sigal et al. also showed that exercise programs can considerably reduce blood glucose [26]. 
Table 2 Comparison of anthropometric measurements between treatment groups during the study

\begin{tabular}{|c|c|c|c|c|}
\hline Variable & Pre-test & Post-test & $p$ value & Within-group $p$ value \\
\hline \multicolumn{5}{|l|}{ Weight (kg) } \\
\hline Intervention group & $86.44 \pm 10.78$ & $82.52 \pm 11.51$ & 0.24 & $p<.001$ \\
\hline Comparison group & $83.04 \pm 9.65$ & $79.66 \pm 10.17$ & & $p<.001$ \\
\hline$p$ value & 0.1 & 0.19 & & $\ldots \ldots \ldots \ldots \ldots$ \\
\hline \multicolumn{5}{|l|}{ BMI $\left(\mathrm{kg} / \mathrm{m}^{2}\right)$} \\
\hline Intervention group & $27.46 \pm 4.79$ & $26.40 \pm 4.04$ & 0.52 & $p=.012$ \\
\hline Comparison group & $26.32 \pm 3.51$ & $25.58 \pm 2.82$ & & $p=.013$ \\
\hline$p$ value & 0.17 & 0.243 & & $\ldots \ldots \ldots \ldots \ldots$ \\
\hline \multicolumn{5}{|c|}{ Waist circumference (cm) } \\
\hline Intervention group & $102.50 \pm 6.27$ & $100.2 \pm 5.67$ & 0.96 & $p<.001$ \\
\hline Comparison group & $100.32 \pm 8.22$ & $98.04 \pm 9.40$ & & $p<.001$ \\
\hline$p$ value & 0.14 & 0.17 & & $\ldots \ldots \ldots \ldots$ \\
\hline
\end{tabular}

One of the limitations of this study was that liver biopsy was not applied to determine histological response. In this study, the diagnosis of non-alcoholic fatty liver was based on ultrasonography, while the liver biopsy is the standard golden method for the diagnosis of non-fatty liver.

\section{Conclusions}

Findings of this study showed that the eradication of HP could considerably improve the ALT index. In the case of changes in the metabolic indicators, the HP had no additional effect. Since the lifestyle modification was applied in two groups, achieving an ideal

Table 3 Comparison of laboratory parameters between treatment groups during the study

\begin{tabular}{|c|c|c|c|c|c|}
\hline Variable & Group & Pre-test & Post-test & $p$ value & Within-group $p$ value \\
\hline \multirow[t]{3}{*}{ Blood glucose (mg/dl) } & Intervention group & $112.56 \pm 8.31$ & $109.54 \pm 8.69$ & 0.23 & $p=.005$ \\
\hline & Comparison group & $112.9 \pm 8.65$ & $107.70 \pm 10.81$ & & $p=.001$ \\
\hline & Between-group $p$ value & 0.84 & 0.35 & & \\
\hline \multirow[t]{3}{*}{ Total cholesterol (mg/dl) } & Intervention group & $209.48 \pm 14.42$ & $180.68 \pm 14.51$ & 0.71 & $p<.001$ \\
\hline & Comparison group & $206.28 \pm 6.61$ & $180.12 \pm 7.50$ & & $p<.001$ \\
\hline & Between-group $p$ value & 0.157 & 0.809 & & \\
\hline \multirow[t]{3}{*}{ Triglyceride (mg/dl) } & Intervention group & $148.22 \pm 18.52$ & $110.06 \pm 19.35$ & 0.73 & $p<.001$ \\
\hline & Comparison group & $145.98 \pm 19.88$ & $106 \pm 13.96$ & & $p<.001$ \\
\hline & Between-group $p$ value & 0.56 & 0.23 & & \\
\hline \multirow[t]{3}{*}{$\mathrm{HDL}(\mathrm{mg} / \mathrm{dl})$} & Intervention group & $46.46 \pm 4.01$ & $48.98 \pm 4.32$ & 0.48 & $p<.001$ \\
\hline & Comparison group & $46.50 \pm 6.90$ & $49.58 \pm 6.63$ & & $p<.001$ \\
\hline & Between-group $p$ value & 0.97 & 0.59 & & \\
\hline \multirow[t]{3}{*}{ LDL (mg/dl) } & Intervention group & $133.94 \pm 4.85$ & $111.42 \pm 6.37$ & 0.1 & $p<.001$ \\
\hline & Comparison group & $132.52 \pm 3.44$ & $111.26 \pm 10.67$ & & $p<.001$ \\
\hline & Between-group $p$ value & 0.09 & 0.92 & & \\
\hline \multirow[t]{3}{*}{ AST (mg/dl) } & Intervention group & $44.14 \pm 16.67$ & $37.72 \pm 8.45$ & 0.06 & $p=.026$ \\
\hline & Comparison group & $43.52 \pm 11.52$ & $41.06 \pm 8.42$ & & $p=.036$ \\
\hline & Between-group $p$ value & 0.83 & 0.051 & & \\
\hline \multirow[t]{3}{*}{ ALT (mg/dl) } & Intervention group & $64.02 \pm 22.26$ & $48.12 \pm 11.52$ & 0.012 & $p<.001$ \\
\hline & Comparison group & $59.60 \pm 19.07$ & $53.52 \pm 14.02$ & & $p<.001$ \\
\hline & Between-group $p$ value & 0.28 & 0.038 & & \\
\hline
\end{tabular}


body weight could result in the sustained biochemical improvement. Given the limitations expressed in the diagnosis of the disease, for future studies, it is recommended to use biopsy and magnetic resonance elastography (MRE) to diagnose and MRE to follow up.

\section{Abbreviations}

ALT: Alanine aminotransferase; AST: Aspartate aminotransferase; HDL: Highdensity lipoprotein; HP: Helicobacter pylori; LDL: Low-density lipoprotein; NAFL: Non-alcoholic fatty liver; NAFLD: Non-alcoholic fatty liver disease; NASH: Non-alcoholic steatohepatitis

\section{Acknowledgements}

The researchers would like to acknowledge and appreciate the contributions of all clinical residents of the Qazvin University of Medical Sciences who helped in conducting the present study.

\section{Authors' contributions}

All authors read and approved the final manuscript. AK did the design, data gathering, and manuscript preparation. AS did the data gathering, analysis, and manuscript preparation. EH did the data gathering and manuscript preparation. ZA did the data gathering and manuscript preparation. AH did the design, data gathering, analysis, and manuscript preparation.

\section{Funding}

Deputy for research of Qazvin University of Medical Sciences.

\section{Availability of data and materials}

Data and materials were available for study.

\section{Ethics approval and consent to participate}

This study was approved by the Ethics Committee of Qazvin University of Medical Sciences and the participation of individuals was subject to a written consent (Ethics committee reference number: 28/20/9669).

\section{Consent for publication}

\section{Not applicable.}

\section{Competing interests}

The authors declare that they have no competing interests.

\section{Author details}

${ }^{1}$ Clinical Toxicology, Metabolic Diseases Research Center, Qazvin University of Medical Sciences, Qazvin, Iran. ²Department of Occupational Health Engineering, Shahid Beheshti University of Medical Sciences, Tehran, Iran. ${ }^{3}$ Department of Internal Medicine, Metabolic Disease Research Center, Qazvin University of Medical Sciences, Qazvin, Iran. ${ }^{4}$ Gastroenterologist Metabolic Diseases Research Center, Qazvin University of Medical Sciences, Qazvin, Iran.

\section{Received: 17 July 2019 Accepted: 15 August 2019}

\section{Published online: 10 October 2019}

\section{References}

1. Benedict M, Zhang X (2017) Non-alcoholic fatty liver disease: an expanded review. World J Hepatol 9(16):715

2. Neuschwander-Tetri BA (2017) Non-alcoholic fatty liver disease. BMC Med 15(1):45

3. Engin AB, Engin A (2017) Obesity and lipotoxicity: Springer

4. Cai O, Huang Z, Li M, Zhang C, Xi F, Tan S (2018) Association between Helicobacter pylori infection and nonalcoholic fatty liver disease: a singlecenter clinical study. Gastroenterol Res Pract 2018:8040262 Pubmed Central PMCID: PMC5828541. Epub 2018/03/13. eng

5. Kang S, Kim D (2016) PTH-112 association between Helicobacter pylori infection and nonalcoholic fatty liver disease in the United States. BMJ Publishing Group 65: A273-A274

6. Malfertheiner P, Megraud F, O'Morain CA, Gisbert JP, Kuipers EI, Axon AT et al (2017) Management of Helicobacter pylori infection-the Maastricht V/Florence consensus report. Gut 66(1):6-30 PubMed PMID: 27707777. Epub 2016/11/02. eng

7. Burucoa C, Axon A (2017) Epidemiology of Helicobacter pylori infection. Helicobacter 22(Suppl 1):e12403 PubMed PMID: 28891138. Epub 2017/09/12. eng
8. Eusebi LH, Zagari RM, Bazzoli F (2014) Epidemiology of Helicobacter pylori infection. Helicobacter 19(Suppl 1):1-5 PubMed PMID: 25167938. Epub 2014/08/30. eng

9. Leja M, Axon A, Brenner H (2016) Epidemiology of Helicobacter pylori infection. Helicobacter 21(Suppl 1):3-7 PubMed PMID: 27531531. Epub 2016/08/18. eng

10. Franceschi F, Gasbarrini A, Polyzos SA, Kountouras J (2015) Extragastric diseases and Helicobacter pylori. Helicobacter 20(Suppl 1):40-46 PubMed PMID: 26372824. Epub 2015/09/16. eng

11. Nasif WA, Mukhtar MH, Nour Eldein MM, Ashgar SS (2016) Oxidative DNA damage and oxidized low density lipoprotein in Type II diabetes mellitus among patients with Helicobacter pylori infection. Diabetol Metab Syndr 8: 34 PubMed PMID: 27148410. eng

12. Taylor NS, Fox JG, Yan L (1995) In-vitro hepatotoxic factor in Helicobacter hepaticus, H. pylori and other Helicobacter species. J Med Microbiol 42(1): 48-52 PubMed PMID: 7739025. Epub 1995/01/01. eng

13. Takuma Y (2011) Helicobacter pylori infection and liver diseases. Gan To Kagaku Ryoho 38(3):362-364 PubMed PMID: 21403438. Epub 2011/03/16. jpn

14. Jamali R, Mofid A, Vahedi H, Farzaneh R, Dowlatshahi S (2013) The effect of helicobacter pylori eradication on liver fat content in subjects with nonalcoholic Fatty liver disease: a randomized open-label clinical trial. Hepat Mon 13(12):e14679 PubMed PMID: 24358044. eng

15. Hashemi MR, Rahnavardi M, Bikdeli B, Dehghani ZM (2006) H pylori infection among 1000 southern Iranian dyspeptic patients. World J Gastroenterol 12(34):5479-5482 PubMed PMID: 17006984. Epub 09/14. eng

16. Lankarani KB, Ghaffarpasand F, Mahmoodi M, Lotfi M, Zamiri N, Heydari ST et al (2013) Non alcoholic fatty liver disease in southern Iran: a population based study. Hepat Mon 13(5):e9248 PubMed PMID: 23922564 eng

17. Ambade VN, Sharma Y, Somani BL (1998) Methods for estimation of blood glucose : a comparative evaluation. Med J Armed Forces India 54(2):131 PubMed PMID: 28775446. Pubmed Central PMCID: PMC5531325. Epub 1998/04/01. eng

18. Jia KK, Zhang J (2010) Evaluation of five routine glucose methods on an Olympus AU5400 analyzer using the CDC hexokinase reference method. Clin Chem Lab Med 48(3):361-364 PubMed PMID: 20170396. Epub 2010/02/23. eng

19. Knopfholz J, Disserol CC, Pierin AJ, Schirr FL, Streisky L, Takito LL et al (2014) Validation of the friedewald formula in patients with metabolic syndrome. Cholesterol 2014:261878 PubMed PMID: 24672715. Pubmed Central PMCID: PMC3941209. Epub 2014/03/29. eng

20. Jamali R, Khonsari M, Merat S, Khoshnia M, Jafari E, Bahram Kalhori A et al (2008) Persistent alanine aminotransferase elevation among the general Iranian population: prevalence and causes. World J Gastroenterol 14(18):2867-2871 PubMed PMID: 18473412. Pubmed Central PMCID: PMC2710729. Epub 2008/05/14. eng

21. Polyzos SA, Nikolopoulos P, Stogianni A, Romiopoulos I, Katsinelos P, Kountouras J (2014) Effect of Helicobacter pylori eradication on hepatic steatosis, NAFLD fibrosis score and HSENSI in patients with nonalcoholic steatohepatitis: a MR imaging-based pilot open-label study. Arq Gastroenterol 51(3):261-268 PubMed PMID: 25296089. Epub 2014/10/09. eng

22. Okushin K, Takahashi Y, Yamamichi N, Shimamoto T, Enooku K, Fujinaga H et al (2015) Helicobacter pylori infection is not associated with fatty liver disease including non-alcoholic fatty liver disease: a large-scale crosssectional study in Japan. BMC Gastroenterol 15:25 PubMed PMID: 25880912. Pubmed Central PMCID: PMC4349671. Epub 2015/04/17. eng

23. Della Pepa G, Vetrani C, Lombardi G, Bozzetto L, Annuzzi G, Rivellese AA (2017) Isocaloric dietary changes and non-alcoholic fatty liver disease in high cardiometabolic risk individuals. Nutrients 9(10):1065

24. Slentz CA, Bateman LA, Willis LH, Shields AT, Tanner CJ, Piner LW et al (2011) Effects of aerobic vs. resistance training on visceral and liver fat stores, liver enzymes, and insulin resistance by HOMA in overweight adults from STRRIDE AT/RT. Am J Physiol Endocrinol Metab 301(5):E1033-E1039 PubMed PMID: 21846904. Pubmed Central PMCID: PMC3214001. Epub 2011/08/19. eng

25. Park SK, Park JH, Kwon YC, Kim HS, Yoon MS, Park HT (2003) The effect of combined aerobic and resistance exercise training on abdominal fat in obese middle-aged women. J Physiol Anthropol Appl Hum Sci 22(3):129135 PubMed PMID: 12808225. Epub 2003/06/17. eng

26. Sigal RJ, Kenny GP, Boule NG, Wells GA, Prud'homme D, Fortier M et al (2007) Effects of aerobic training, resistance training, or both on glycemic control in type 2 diabetes: a randomized trial. Ann Intern Med 147(6):357369 PubMed PMID: 17876019. Epub 2007/09/19. eng

\section{Publisher's Note}

Springer Nature remains neutral with regard to jurisdictional claims in published maps and institutional affiliations. 